\title{
Risperidone versus zuclopenthixol in the treatment of schizophrenia with substance abuse comorbidity: a long-term randomized, controlled, crossover study
}

\author{
Gabriel Rubio* \\ Isabel Martínez* \\ Ana Recio** \\ Guillermo Ponce*** \\ Francisco López-Muñoz ${ }^{\star * * *}$ \\ Cecilio Alamo**** \\ Miguel Ángel Jiménez-Arriero*** \\ Tomás Palomo*** \\ * Mental Health Services of Retiro, Madrid \\ ** Mental Health Centre of Ciudad Lineal, \\ Madrid \\ *** Psychiatry Service, "12 de Octubre" \\ University Hospital, Madrid \\ **** Pharmacology Department, Faculty of \\ Medicine, University of Alcalá, Madrid
}

SPAIN

\begin{abstract}
Background: Substance use disorders (SUDs) are present in more than $50 \%$ of subjects diagnosed with schizophrenia. However, there are no controlled studies assessing the efficacy of antipsychotic drugs in this subgroup of patients. The aim of the present work was to compare the efficacy of risperidone and zuclopenthixol in a sample of schizophrenic subjects with dual diagnosis.

Method: Thirty-three male were selected for treatment with risperidone, while another 33 were treated with zuclopenthixol. Substances most commonly used were alcohol, cannabis (both $82 \%$ ) and cocaine (32\%). Patients were randomized and treated for the first six months with one antipsychotic and the second six months with the other antipsychotic. Psychopathological and clinical scales were used every two months. Participants received training on how to reduce their consumption of substances (Substance Abuse Management Module, SAMM).

Results: During the first six months risperidone group patients presented fewer positive urine tests and showed better compliance with the SAMM programme. In the second period the patients treated with risperidone significantly improved their scores on the PANSSnegative subscale. Differences between the CGIs indicated that the subjects who moved
\end{abstract}


from risperidone to zuclopenthixol worsened, while those who moved from zuclopenthixol to risperidone significantly improved.

Conclusions: Risperidone was more effective than zuclopenthixol in improving the symptoms of schizophrenia and substance use.

Received 21 August 2005

Accepted 10 January 2006

\section{Introduction}

Drug abuse is highly prevalent in schizophrenic patients. An estimated $50 \%$ of subjects diagnosed with schizophrenia also present substance use disorders (SUDs), compared to $12 \%$ of the general population ${ }^{1}$. Tobacco, cannabis, alcohol and cocaine are the substances most commonly used by these patients ${ }^{1,2}$. It is considered that substance abuse hastens the onset of schizophrenia, aggravates its symptoms, leads to poorer therapeutic compliance and increases hospitalizations in this population ${ }^{3,4}$. It also heightens the risk of HIV and other infections 5 .

Despite high comorbidity and the impact of substance use on the outcome of schizophrenia, controlled studies assessing the effectiveness of pharmacological treatment in this type of patient are rare. In a recent review on the pharmacological treatment of schizophrenic patients with SUDs it was found that of the 17 studies involved, none was controlled, and in 12 of them atypical antipsychotics had been used ${ }^{6}$. In a recent 6week, open study, risperidone decreased craving and relapse for cocaine more than typical neuroleptics in subjects with schizophrenia and cocaine dependence ${ }^{7}$. However, the difficulty of therapeutic compliance in patients with dual diagnosis means that in everyday practice many psychiatrists tend to prefer using depot neuroleptics in order to ensure better compliance and to reduce exacerbations and hospitalization in these patients ${ }^{8}$.

Bearing in mind the absence of controlled studies in this field, we opted to carry out the first controlled study of risperidone versus zuclopenthixol in subjects with schizophrenia and SUD. Risperidone is an atypical antipsychotic widely used in the treatment of patients with schizophrenia ${ }^{9}$. Furthermore, it has been used in different open studies with patients diagnosed with schizophrenia and drug abuse disorders ${ }^{10,11}$. Zuclopenthixol is a well established thioxanthene antipsychotic. Several controlled studies have shown this drug to be just as effective as chlorpromazine ${ }^{12}$ and risperidone ${ }^{13}$ in the treatment of patients with schizophrenia. It can be administered intramuscularly (depot $200 \mathrm{mg} / 1 \mathrm{ml}$ ) or orally. Depot administration can improve therapeutic compliance in low-compliant patients ${ }^{14}$.

The objective of the present study was to compare the efficacy of the two drugs in improving the symptoms of schizophrenia in subjects with dual diagnosis. At the same time we aimed through this comparison to determine which antipsychotic drug would improve substance abuse and produce the better compliance with the psychotherapeutic programme for reducing or ceasing substance use. Only male subjects have been selected because substance abuse is less frequent in female. 


\section{Method}

Chronic schizophrenic patients with SUDs (substance use disorders) were enrolled for a randomized, controlled, carried out at two outpatient centers in Spain. The study was performed in accordance with the Helsinki Declaration (1964). Approval of the protocol by appropriate local ethics committees was also secured, and informed consent was obtained in all cases.

\section{Patients}

To be eligible for inclusion, patients had to be male, aged between 18 and 65, and have a diagnosis of schizophrenia and SUD for substances other than caffeine and nicotine, according to the DSM-IV (15). Patients were excluded from the study if they had a clinically significant organic or neurological disorder, serious psychotic disorder other than schizophrenia, clinically relevant abnormalities in laboratory tests at baseline, neutropenia or thrombocytopenia, or a clinically relevant abnormal ECG.

Patients were selected during their stay in hospital. They had been admitted due to a worsening of their psychotic symptomatology. Once stabilized, and before being discharged, they were asked if they would participate in the study. Those who accepted signed the informed consent document. Of 124 patients interviewed (all males), 66 agreed to participate in the study.

\section{Study design}

\section{Justification of the design}

We chose an open design in order to avoid the typical complications that may arise in double-blind studies with abuser patients.
The emergence of adverse reactions and/or severe side effects may lead blind researchers to exclude the patient from the study, when in many cases what are involved are secondary reactions to substance use.

It was in order to avoid the possible bias resulting from assessment of the patient by the clinician (who was obviously aware of the treatment prescribed) that we opted for the inclusion of blind assessors. We used a long follow-up period in view of the fact that changes of habit related to the use of substances are difficult and take considerable time. Furthermore, one of the advantages of using a crossover study is that each patient can be compared in his reaction to the two drugs used, thus reducing the bias that may have arisen with randomization in such a small sample. It can be said, therefore, that the conditions of the study are as close as possible to those of normal practice.

\section{Design}

Selection of the patients took place while they were in hospital. When informed consent was obtained they were allocated alternately to receive risperidone or zuclophentixol. Subjects remained in hospital for 7-15 days more until being referred to their outpatient centre to continue the pharmacological treatment for 12 months.

Before discharge from hospital they were given a baseline interview. Patients had a weekly consultation with their psychiatrist, who was responsible for prescription and monitoring of the risperidone and zuclopenthixol and for the programme to prevent substance use relapses. At each weekly visit patients also took a urine test to check for alcohol, opiates, cocaine and cannabis.

After six months of the study it was proposed to the patients to change the pharma- 
cological treatment, so that those who were receiving risperidone began to take zuclopenthixol, and vice-versa. They continued to meet their psychiatrist once a week for the clinical check and the urine test. Every two months they were interviewed by a monitor with no knowledge of their pharmacological treatment, until the second sixmonth follow-up period was complete (total 52 weeks).

At any point the patient could ask to drop out of the study. Patients' failure to attend the interviews or to take the urine test during follow-up was not considered sufficient reason to exclude them from the study. Patients who during the follow-up period had to be admitted to a psychiatric hospital were given the opportunity of continuing the study if they wished. If the patient failed to attend the bimonthly visit (e.g., because he was hospitalized), the interview was postponed until it was possible for him to attend.

\section{'Blind' researchers}

The outcome data were collected by researchers who were blind to the drug taken by the patients. Every two months they interviewed subjects and filled out the different efficacy and safety scales.

\section{Assessment instruments}

\section{Evaluation of efficacy}

Efficacy was assessed by means of the Positive and Negative Syndrome Scale (PANSS $)^{16}$ for schizophrenia and the Clinical Global Impression Scale ${ }^{17}$. The PANSS includes 30 items, which measure both positive and negative symptoms, as well as general psychopathology, by means of a semistructured patient interview.
Evaluation of SUDs and use of substances

Severity of the complications of substance use was assessed by the Addiction Severity Index $(\mathrm{ASI})^{18}$. This is a semi-structured interview that assesses the following areas: psychoactive drug abuse; medical problems; legal problems; family situation; social problems; and employment and financial situation.

Although patients were asked about substance use in each one of the interviews, we opted to include, as measures of substance-use assessment, the Clinical Global Impression (CGI) Scale and detection of substances in urine in the weekly tests. Reactive strips were used for alcohol, cocaine, opiates and cannabis (Instacheck, San Diego, USA).

\section{Evaluation of safety}

Extrapyramidal symptoms were evaluated using the Extrapyramidal Symptom Rating Scale $(E S R S)^{19}$, which consists of a questionnaire to evaluate the subjective effects, a detailed clinical evaluation of parkinsonism, dystonia and dyskinesia and 2 global impressions of the severity of parkinsonism and dyskinesia. The effects of other adverse events on the patients' daily activities were evaluated by means of the UKU Side Effect Rating Scale ${ }^{20}$.

\section{Psychotherapeutic programme: Substance Abuse Management Module (SAMM)}

This programme was developed by Roberts et al. ${ }^{21}$, and is made up of the following modules: basic training (8 sessions), skills training (9 sessions) and practical sessions. It is based on a cognitive-behavioural approach and designed specifically for patients diagnosed with schizophrenia and 
substance abuse. All the patients attended this type of psychotherapeutic session weekly until completion of 24 sessions (first sixmonth period). During the second period the patients were encouraged to continue with the basic aspects learned on the programme.

\section{Outcome variables}

The main psychopathological efficacy variables were reduction in the scores of the different subscales of the PANSS and reduction in the CGI related to the schizophrenia symptoms (CGI-schizophrenia symptoms). We considered as therapeutic efficacy a reduction of at least $20 \%$ in the total PANSS score with respect to the baseline situation.

The secondary outcome variables were:

a) Substance abuse: the number of positive urine tests during the two study periods; changes in the CGI for substance use (CGIsubstance abuse) and time elapsed before first positive urine test (or number of patients with negative tests at the end of the study).

b) Compliance with the SAMM programme was determined by the number of times participants attended the programme sessions during the study. Compliance was considered to be adequate when they attended 18 sessions or more in each period $(75 \%$ of the sessions). In order to assess the impact of the change in antipsychotic drug on compliance, we considered that there could be "no changes", "worsening" or "improvement", according to whether the number of sessions in the two periods was similar (no changes), higher (improvement) or lower (worsening), respectively.

c) Safety variables were reduction of ESRS, changes in UKU, and number of patients in which antiparkinsonian drugs were used in each group.

In order to determine whether there were clinical changes due to the change of antipsychotic, patients were classified according to CGI-schizophrenia symptoms and CGI-substance abuse at month 6 and month 12. There were three possible situations: no clinical changes (CGI at months 6 and 12 identical), improvement (CGI at month 12 better than at month 6) and worsening (CGI at month 12 poorer than at month 6).

\section{Statistical analysis}

Measures of efficacy and safety were analyzed according to the intent-to-treat principle. Unpaired $t$ tests were used to analyze differences between treatment groups. Dichotomous variables were evaluated using Pearson's $\chi^{2}$ test or two-tailed Fisher's exact test. Variations in each of the variables in a given treatment group and the changes between treatment periods were analyzed using two-tailed paired $t$ test. A last observation carried forward (LOCF) model was used for repeated-measures analysis and a significance level of 0.05 was employed to characterize the results. The number of patients with negative urine tests at the end of month 6 was determined by means of the KaplanMeier product-limit survival test.

We used different regression models to explain the clinical response of the psychopathology (PANSS-total $<20 \%$ of baseline), for clinical response to substance use (2/3 of the urine controls negative) and for compliance with the psychotherapeutic programme ( $75 \%$ attendance at sessions) at the end of the first and second treatment periods. 


\section{Results}

The demographic and baseline characteristics did not differ significantly between the two treatment groups (Table I). The commonest diagnoses were paranoid, residual and undifferentiated schizophrenia. The commonest SUDs were for nicotine, alco- hol and cannabis. There were no differences in the severity of the addiction evaluated by means of the ASI, nor in the family antecedents of schizophrenia or substance abuse. Patients were treated with oral neuroleptic drugs prior to commencement of the trial (haloperidol $-60 \%-$, zuclopenthixol $-20 \%-$ and chlorpromazine $-20 \%-)$.

Table I

Demographic and clinical characteristics of treatment groups.

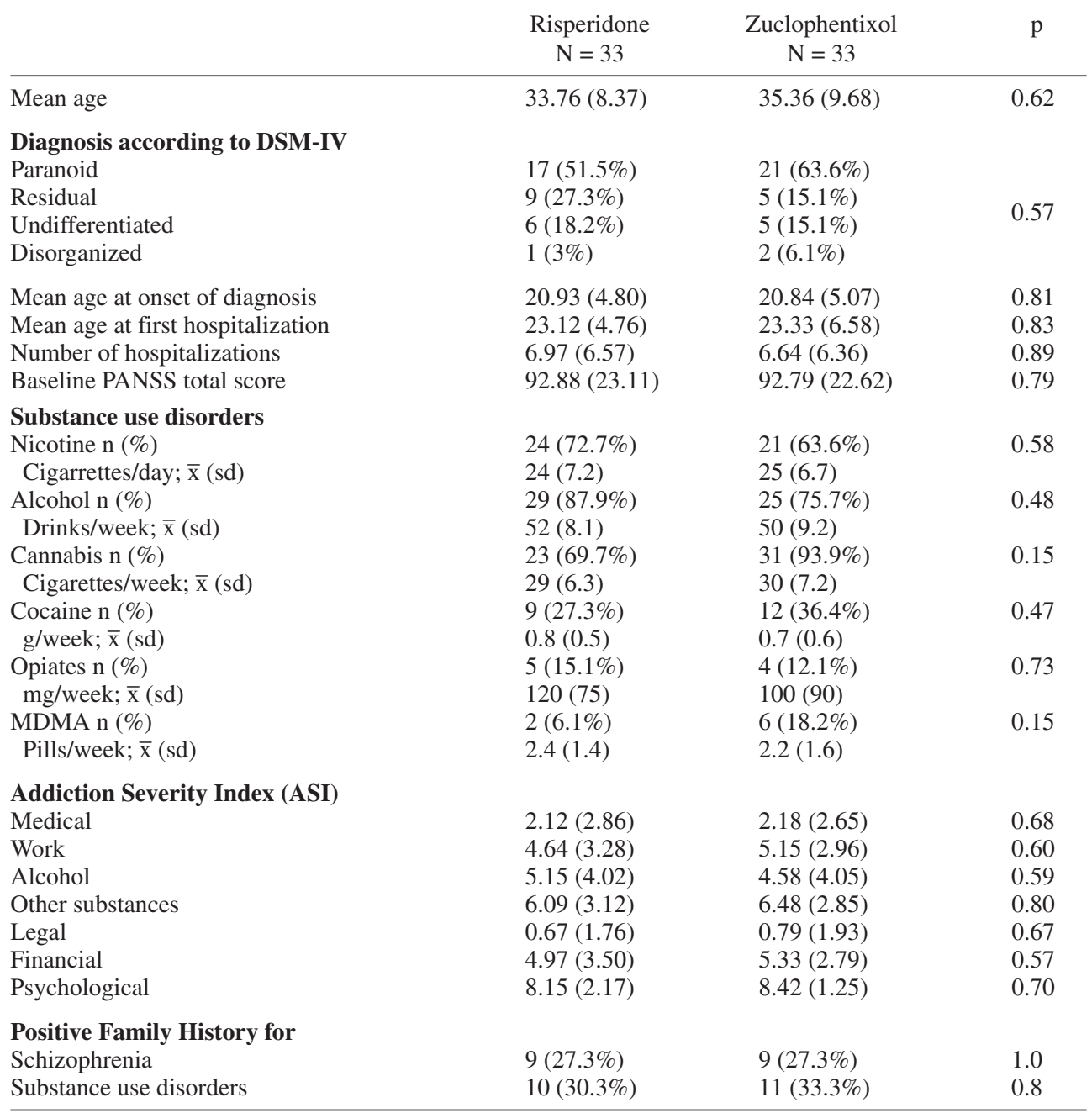

Equivalences: A drink $=10 \mathrm{~g}$ ethanol, 1 cannabis cigarette $=1-2$ Euros; $1 \mathrm{~g}$ of street cocaine $=36-60$ Euros, $100 \mathrm{mg}$ of street heroin $=2-4$ Euros, 1 pill of MDMA $=3-6$ Euros 


\section{First period (from baseline to 6 months)}

During the first period, four patients dropped out of the study, three from the zuclopenthixol group and one from that of risperidone. Two of these were re-hospitalized and spent 6 months as inpatients, while the other two did not agree to attend the programme for the management of drug consumption. Three patients from the risperidone group and five from the zuclopenthixol group needed to be admitted to psychiatric hospital during this period due to exacerbation of their psychopathological symptoms. Mean doses at the end of the first period were $6.4 \mathrm{mg} /$ day (range 3-12) for risperidone and $38 \mathrm{mg} /$ day (range 10-100) for zuclopenthixol. In $28(84.8 \%)$ patients of the zuclopenthixol group we used the depot formulation (1 administration every 21-30 days). In these patients, together with the depot, the daily dose of zuclopenthixol by mouth was $15 \mathrm{mg} /$ day (range 10-50 mg). Results of this period can be seem in Table II.

Table II

Results of outcome variables during the study.

\begin{tabular}{|c|c|c|c|c|}
\hline & \multicolumn{2}{|c|}{$\begin{array}{l}\text { First period } \\
\text { (At } 6 \text { month) }\end{array}$} & \multicolumn{2}{|c|}{$\begin{array}{l}\text { Second period } \\
\text { (At } 12 \text { month) }\end{array}$} \\
\hline & $\begin{array}{l}\text { Risperidone } \\
\quad(\mathrm{n}=32)\end{array}$ & $\begin{array}{l}\text { Zuclopenthixol } \\
\qquad(\mathrm{n}=30)\end{array}$ & $\begin{array}{l}\text { Risperidone } \\
\quad(\mathrm{n}=32)\end{array}$ & $\begin{array}{l}\text { Zuclopenthixol } \\
\qquad(\mathrm{n}=30)\end{array}$ \\
\hline $\begin{array}{l}\text { Efficacy (Evaluation at the end } \\
\text { of the period of study) }\end{array}$ & Mean (SD) & Mean (SD) & Mean (SD) & Mean (SD) \\
\hline $\begin{array}{l}\text { PANSS-total } \\
\text { PANSS-positive } \\
\text { PANSS-negative } \\
\text { PANSS-general }\end{array}$ & $\begin{array}{l}66.81(21.34) \\
13.23(4.20) \\
18.8(5.31) \\
34.7(9.26)\end{array}$ & $\begin{array}{l}73.68(21.1) \\
14.42(5.18) \\
22.9(7.40) \\
36.32(11.92)\end{array}$ & $\begin{array}{l}65.81(19.4) \\
12.68(6.51) \\
18.10(5.62) \\
33.87(11.20)\end{array}$ & $\begin{array}{l}73.29(21.0) \\
14.3(5.21) \\
24.65(8.01) \mathrm{a} \\
34.42(11.21)\end{array}$ \\
\hline Substance abuse & Mean (SD) & Mean (SD) & Mean (SD) & Mean (SD) \\
\hline $\begin{array}{l}\text { Tests performed during } \\
\text { the period of study }\end{array}$ & $19.76(3.6)$ & $17.55(4.3)^{b}$ & $19.9(1.8)$ & $19.77(2.64)$ \\
\hline $\begin{array}{l}\text { Total positive tests during } \\
\text { the period of study }\end{array}$ & $8.67(3.0)$ & $10.36(3.1)^{\mathrm{c}}$ & $7.48(2.8)$ & $9.03(3.7) \mathrm{d}$ \\
\hline Compliance & Mean (SD) & Mean (SD) & Mean (SD) & Mean (SD) \\
\hline $\begin{array}{l}\text { Number of programme sessions } \\
\text { attended }\end{array}$ & $19.76(3.6)$ & $17.55(4.3)^{\mathrm{e}}$ & $19.9(1.8)$ & $19.77(2.64)$ \\
\hline \multicolumn{5}{|l|}{ Compliance* } \\
\hline Good & $31(93.9 \%)$ & $13(39.4 \%)^{\mathrm{f}}$ & $29(87.8 \%)$ & $28(84.8 \%)$ \\
\hline Poor & $2(6.1 \%)$ & $20(60.6 \%)$ & $4(12.1 \%)$ & $5(15.1 \%)$ \\
\hline $\begin{array}{l}\text { Safety(Evaluation at the end of } \\
\text { the period of study) }\end{array}$ & Mean (SD) & Mean (SD) & Mean (SD) & Mean (SD) \\
\hline ESRS & $1.94(0.6)^{\mathrm{g}}$ & $2.85(1.1)$ & $2.42(0.8)$ & $2.65(0.6)^{\mathrm{h}}$ \\
\hline
\end{tabular}

PANSS-Total: Total PANSS score; PANSS-positive: PANSS-positive subscale; PANSS-negative: PANSSnegative subscale; PANSS-general: PANSS-General Psychopathology subscale.

ESRS: Extrapyramidal Symptom Rating Scale.

$(*)$ Good compliance: $>75 \%$ of the sessions ( $>18$ in each period)

Differences between groups:

a) $\mathrm{t}=3.10, \mathrm{p}=0.003 ; \mathrm{b}) \mathrm{t}=2.50, \mathrm{p}=0.01 ; \mathrm{c}) \mathrm{t}=-2.20, \mathrm{p}=0.03$; $) \mathrm{t}=1.84, \mathrm{p}=0.07$; $) \mathrm{t}=2.50, \mathrm{p}=0.01$;

f) $\left.\left.\chi^{2}=10.43, \mathrm{df}=1, \mathrm{p}=0.001 ; \mathrm{g}\right) \mathrm{t}=-3.74, \mathrm{p}=0.00 ; \mathrm{h}\right) \mathrm{t}=2.57, \mathrm{p}=0.013$. 


\section{Efficacy}

None of the scores in the PANSS subscales for the first period indicated statistically significant differences. Also by month $6,57.6 \%$ and $48.5 \%$ had reduced their total PANSS by more than $20 \%$, respectively

\section{Substance abuse}

The number of positive urine tests was significantly higher in the zuclopenthixol group than in that of risperidone. All the patients consumed substances during the first 6 months, even though the first positive urine test occurred in the ninth week for the zuclopenthixol group (CI 7-10) and the seventh for the risperidone group (CI 5-8) (Longrak 0.07).

\section{Compliance}

Patients treated with risperidone attended a significantly larger number of SAMM programme sessions than those of the zuclopenthixol group. In fact, $93 \%$ of those in the risperidone group were classified as good compliers.

\section{Drug Safety}

There was a more significant reduction in the scores on the scales for EPS and UKU ( $t$ $=1.92, \mathrm{p}=0.04)$ in the risperidone group. Antiparkinsonian drugs were used more frequently in the zuclopenthixol group (48.5\% vs $27 \%, \chi^{2}=3.23$, df $=1, p=0.07$ ).

\section{Second period (from month 6 to month 12)}

During the second period there were no dropouts, and 9 patients needed to be admitted to psychiatric hospital due to clinical relapses (four from the risperidone group and five from that of zuclopenthixol). Mean doses at the end of the second period were 6 $\mathrm{mg} /$ day (range 3-9) for risperidone and 35 mg/day (range 10-100) for zuclopenthixol. In 27 patients of the zuclopenthixol group we used the depot formulation (1 administration every 21-30 days). In these patients, together with the depot, the daily dose of zuclopenthixol by mouth was $12 \mathrm{mg} /$ day (range 10-50 mg).

\section{Efficacy}

There were significant differences only in the negative PANSS in the evaluations at month 12 of the study. The percentage of subjects with a PANSS score $20 \%$ lower than that of baseline was higher in the group treated with risperidone $\left(\chi^{2}=2.65, \mathrm{df}=1, \mathrm{p}\right.$ $=0.10)$.

\section{Substance abuse}

Total number of positive urine tests was significantly higher in the zuclopenthixol group than in that of risperidone.

\section{Compliance}

Number of sessions attended by each treatment group was similar, so that the percentage of subjects included in the "good compliance" group was comparable for the two groups.

\section{Drug Safety}

Risperidone group subjects presented significantly lower scores at month 12 in the ESRS and UKU $(\mathrm{t}=2.24, \mathrm{p}=0.03)$. In the group zuclopenthixol group the percentage of patients needing concomitant antiparkinsonian drugs was higher $(\mathrm{n}=15)$ than in the risperidone group $(\mathrm{n}=8)(24.2 \%$ vs. 42.4 , $\left.\chi^{2}=3.33, \mathrm{df}=1, \mathrm{p}=0.06\right)$.

\section{Changes between periods (Table III)}

Patients treated initially with zuclopenthixol continued to improve with regard 
to both their schizophrenia symptoms and their substance use when they changed to risperidone. On comparing the degree of compliance between the two periods, those patients that had initially received zuclopenthixol improved on changing to risperidone $(27 \%)$, while of those treated initially with risperidone, $15 \%$ worsened on changing to zuclopenthixol.

\section{Logistic regression models for explaining the prognosis}

As regards the models for explaining the reduction of the total PANSS score $>20 \%$, at month 6 the only variable that entered the model was baseline severity of dependence measured with the ASI (Table IV). That is, the more severe the dependence, the lower the risk of a reduction in the total PANSS score. On the other hand, the model for explaining the same variable at month 12 involved severity of dependence measured with the ASI and the antipsychotic treatment received (Table IV). Thus, presenting less severity of dependence and having been treated initially with risperidone were associated with higher probability of the total PANSS score falling $>20 \%$ from the baseline figure.

Table III

Modifications in clinical evaluation after change of treatment group.

Changes in CGI on psychopathological situation after treatment group change (a)

\begin{tabular}{lccl}
\hline $1^{\circ}$ Risperidone and $2^{\circ}$ Zuclopenthixol & $23(69.7 \%)$ & $1(3 \%)$ & $7(21.2 \%)$ \\
$1^{\circ}$ Zuclopenthixol and $2^{\circ}$ Risperidone & $17(51.5 \%)$ & $14(42.4 \%)$ & 0 \\
Changes in CGI on consumption of subtances after treatment group change (b) & \\
$1^{\circ}$ Risperidone and $2^{\circ}$ Zuclopenthixol & $25(75.7 \%)$ & $1(3 \%)$ & $5(15.1 \%)$ \\
$1^{\circ}$ Zuclopenthixol and $2^{\circ}$ Risperidone & $16(48.5 \%)$ & $15(45.4 \%)$ & 0 \\
Changes in therapeutic compliance (c) $(*)$ & & & $5(15.1 \%)$ \\
$1^{\circ}$ Risperidone and $2^{\circ}$ Zuclopenthixol & $28(84.8 \%)$ & 0 & $2(6.1 \%)$ \\
$1^{\circ}$ Zuclopenthixol and $2^{\circ}$ Risperidone & $22(66.6 \%)$ & $9(27.3 \%)$ &
\end{tabular}

a) $\chi^{2}=19.16, \mathrm{df}=2, \mathrm{p}=0.00$, b) $\chi^{2}=19.22, \mathrm{df}=2, \mathrm{p}=0.00$, c) $\chi^{2}=11.66, \mathrm{df}=2, \mathrm{p}=0.004$

(*) Good compliance: $>75 \%$ of the sessions ( $>18$ sessions in each period)

Table IV

Logistic regression models for explaining the prognosis variables.

\begin{tabular}{|c|c|c|c|c|}
\hline \multirow[b]{2}{*}{ Outcome variable } & \multicolumn{2}{|c|}{ First period } & \multicolumn{2}{|c|}{ Second period } \\
\hline & $\mathrm{OR}(\mathrm{CI})$ & $\mathrm{p}$ & $\mathrm{OR}(\mathrm{CI})$ & $\mathrm{p}$ \\
\hline \multicolumn{5}{|l|}{ Reduction in PANSS-total $>\mathbf{2 0} \%$} \\
\hline Severity of the dependence measured on ASI & $1.19(1.05-1.36)$ & 0.009 & $1.13(0.99-1.29)$ & 0.06 \\
\hline Having been treated with risperidone in the first period & -- & -- & $5.22(1.2-21.8)$ & 0.02 \\
\hline \multicolumn{5}{|l|}{ At least $2 / 3$ of urine drugs tests negative } \\
\hline Severity of the dependence measured on ASI & $1.81(1.26-2.60)$ & 0.001 & $1.81(1.26-2.60)$ & 0.001 \\
\hline Number of hospitalizations since onset of disorder & $2.58(1.38-4.81)$ & 0.001 & $2.58(1.38-4.81)$ & 0.001 \\
\hline Having been treated with risperidone in the first period & $13.1(1.4-119)$ & 0.02 & $13.1(1.4-119)$ & 0.02 \\
\hline \multicolumn{5}{|l|}{ Attendance at $75 \%$ of SAMM programme sessions } \\
\hline Number of hospitalizations since onset of disorder & $1.13(0.99-1.28)$ & 0.05 & -- & -- \\
\hline Having been treated with risperidone in the first period & $17.8(2.02-142)$ & 0.005 & -- & -- \\
\hline
\end{tabular}
No change Improvement Worsening

Changes in clinical status between months 6 and 12 
In the models for explaining the reduction in positive urine tests, the same variables were involved at month 6 and month 12: number of hospitalizations since onset of schizophrenia, severity of dependence measured with the ASI, and type of antipsychotic received during the treatment. That is, greater reduction in positive urine tests was associated with fewer hospitalizations since onset of the disorder, with having used risperidone in the first study period and with less severity of dependence.

Finally, in the model for explaining compliance with the SAMM programme, at month 6 the variables involved were number of hospitalizations since onset of schizophrenia and type of antipsychotic received during the first treatment period. It might therefore be stated that a history of few admissions to psychiatric hospital and using risperidone is associated with better compliance. In the model at month 12 months no variables were involved.

\section{Discussion}

The results of this study indicate that in subjects with schizophrenia and substance abuse, risperidone was more effective than zuclopenthixol in alleviating negative symptomatology and reducing substance use. Those treated with risperidone presented fewer positive urine tests in both study periods. Risperidone also led to more improvement than zuclopenthixol with regard to compliance with the programme for managing substance abuse. Taking into account the results of the different regression models, it can be stated that choice of antipsychotic is relevant for explaining the results related to schizophrenia symptoms, to substance use and to compliance with the psychotherapeutic programme.

Given that this is the first controlled study in a sample of patients with dual diagnosis, it is not possible to make comparisons with similar work, though the differences between the two drugs in schizophrenic subjects have been pointed out elsewhere ${ }^{13}$. Risperidone and zuclopenthixol were equally effective in reducing positive, but not negative symptomatology. The percentage response to risperidone, in our study, is within the range found in other studies carried out in subjects with schizophrenia and without SUD (57\% and $72 \%$ at 6 and 12 months, versus 61$74 \%$ 22,23,24,25. However, percentage response to zuclopenthixol was higher than in other research (44\% in 13). The greater efficacy of risperidone compared to zuclopenthixol, above all in the reduction of negative symptoms, may be explained by the different pharmacological actions of the two drugs. In contrast to zuclopenthixol, risperidone shows a predominance of antagonism at the $5-\mathrm{HT}_{2 \mathrm{~A}}$ receptor, as compared to the $\mathrm{D}_{2}$ receptor ${ }^{26}$. Also, risperidone may potentiate noradrenergic activity, via the active metabolite 9-hydroxyrisperidone ${ }^{27}$.

The hypothesis that the efficacy of risperidone on negative symptoms is a direct effect, and not secondary to improvements on positive, extrapyramidal or depressive symptoms, has been examined ${ }^{28,29}$. Reanalysis of data from the North American risperidone trial showed that the effects of risperidone on negative symptoms were independent of its effects on EPS $^{30}$.

With regard to the reduction in substance use, the results of the present study indicate that risperidone contributes to reducing substance consumption in a consistent way, since, when risperidone is substituted by zuclopenthixol, the positive urine tests 
increase in number. Smelson et al. ${ }^{31}$ showed that individuals with schizophrenia and cocaine dependence treated with risperidone had significantly less cue-elicited craving and relapses than subjects treated with typical antipsychotics. Indirect evidence of the greater efficacy of risperidone can be found in other studies. Where it has been used in the treatment of subjects with psychotic disorders and opiates abuse, it has been shown that $50 \%$ of subjects reduced their use of opiates ${ }^{11}$. Studies in which patients' treatment was changed from classic neuroleptics to atypical antipsychotics (clozapine, olanzapine) have also confirmed the greater efficacy of the latter type for reducing substance use $^{32,33}$.

Indeed, it has been speculated that this type of antipsychotic may form the basis of the principal treatment strategy for acting on negative symptoms and reducing dysphoria and extrapyramidal symptoms ${ }^{6}$. There are several non-exclusive hypotheses justifying this notion. It has been pointed out that patients diagnosed with schizophrenia tend to use substances more frequently than the general population, in an attempt to reduce their states of dysphoria ${ }^{32,34}$, the positive and negative symptoms of the disorder $32,34,35$, 36,37 , and the cognitive deficits related to schizophrenia or psychoactive drugs ${ }^{38}$, or in an attempt to increase mesocortical dopaminergic hypoactivity and alleviate the anhedony associated with their situation ${ }^{39}$. It is also possible that a subgroup of these patients will present greater risk due to the presence of antisocial features or novelty-seeking, modulated by the serotonergic and dopaminergic systems, respectively ${ }^{40}$. The pharmacological characteristics of atypical antipsychotics, and in particular risperidone, and their actions on factors of vulnerability to substance use in this population, may partly explain their efficacy $^{6}$. Moreover, outside the context of patients diagnosed with schizophrenia, it has been suggested that atypical antipsychotics may reduce the use of substances such as alcohol and cocaine ${ }^{31,41,42}$. It has been hypothesized that atypical antipsychotics reduce substance use more than classic neuroleptics due to lower hypersensitivity to $D_{2}$ dopaminergic receptors in mesolimbic pathways $^{43,44}$.

The frequency of extrapyramidal symptoms/signs was higher in the zuclopenthixol group than in that of risperidone at the end of both study periods. Use of antiparkinsonian drugs was also lower in subjects treated with risperidone. Similar results were found on comparing these two antipsychotics in a sample of schizophrenic patients without SUD $^{13}$. The pharmacological differences between the two antipsychotics could explain their different tolerance profiles ${ }^{26}$.

As regards compliance with programmes for managing substance use, it is difficult to find controlled studies in which the effects of pharmacological treatment have been taken into account. Up to now, the objectives of these studies have been to establish or check that the treatment of these patients was possible, and to confirm that more effectiveness was obtained when the schizophrenic and substance abuse disorders were approached within an integrated $\operatorname{model}^{45}$, $46,47,48$.

It has been suggested that one of the possible determining factors in the achievement of medium- and long-term objectives is that patients find the treatment programme useful and that their clinical situation allows them to comply with and accept the content of the therapeutic programme. Thus, a pharmacological treatment, such as risperidone, may be more effective in achieving compliance with the psychotherapeutic programme than classic neuroleptics for two reasons: a) it reduces 
some of the clinical factors that may predispose to the use of drugs (positive and negative symptoms); b) it reduces the reinforcing capacity of drugs of abuse. Thus, patients may experience a greater sense of self-efficacy as they attain partial goals, which in turn would lead to more active involvement in the programme. Similar hypotheses have been put forward to explain the participation of alcohol-dependent subjects in cognitivebehavioural treatments in combination with naltrexone ${ }^{49}$.

In sum, there is a need for further research that would permit clinicians to approach more effectively the treatment of schizophrenics with dual diagnosis, in particular with regard to the best type of antipsychotic for controlling the symptoms. It would also be of interest to determine which type of psychotherapeutic intervention is most appropriate for each type of patient, and works best in combination with the pharmacological treatment.

\section{Limitations}

The results of this study should be considered with some caution, in view of its limitations. Fifty percent of the subjects were excluded in the selection period. It may well be that precisely those most severely affected, in relation to both their psychotic condition and substance abuse, were the ones who declined to participate. Furthermore, all participants were able to be attended as outpatients, which implies that they had at least some sort of family support. Thus, those who were homeless or with inadequate social or family support -and who constitute a group with more serious characteristics- remained outside the study. The fact that the psychiatrists who treated the patients had knowledge of their evolution may also affect the results.
Indeed, during the first period (6 months) there were already signs of marked differences between the two pharmacological treatments, and this may have led the psychiatrists to take more interest in those treated with risperidone, since they evolved better than those of the other group.

\section{Acknowledgements}

Research grant from the Fundación Cerebro y Mente (FCM).

José María Bellón. Servicio de Medicina Preventiva (Preventive Medicine Service). Hospital Universitario Gregorio Marañon, Madrid.

None of the authors has received direct or indirect financial support from the pharmaceuticals industry.

\section{References}

1. Regier DA, Farmer ME, Rae DS, et al. Comorbidity of mental disorders with alcohol and other drug abuse. Results from the Epidemiologic Catchment Area Study. JAMA 1990; 264: 2511-2518.

2. Kavanagh DJ, McGrath J, Saunders JB, et al. Substance Misuse in patients with schizophrenia: epidemiology and management. Drugs 2002; 62: 743-755.

3. Linszen DH, Dingemans PM, Lenior ME. Cannabis abuse and the course of recent-onset schizophrenic disorders. Arch Gen Psychiatry 1994; 51: 273-279.

4. Dixon L. Dual diagnosis of substance abuse in schizophrenia: prevalence and impact on outcomes. Schizophr Res 1999; (Supp 35): s93-s100.

5. Rubio G. Métodos diagnósticos de trastornos psiquiátricos en poblaciones con abuso de drogas. In: Cabrera J ed. Patología Dual. Madrid: Agencia Antidroga; 1998. p. 18-31 
6. Rubio G, Casas M. Revisión del tratamiento de la esquizofrenia en individuos con abuso de drogas. Actas Esp Psiquiatr 2001; 29: 124-130.

7. Smelson DA, Losonczy MF, Davis CW, Kaune M, Williams J, Ziedonis D. Risperidone decreases craving and relapses in individuals with schizophrenia and cocaine dependence. Can J Psychiatry 2002; 47: 671-675.

8. Ziedonis DM, Trudeau K. Motivation to Quit Using Substances Among Individuals With Schizophrenia: Implications for a Motivation-Based Treatment Model. Schizophr Bull 1997; 23: 229-238.

9. Kane JM, Leucht S, Carpenter D, Docherty JP. The expert Consensus Guideline of Psychotic Disorders. Optimizing Pharmacologic Treatment of Psychotic Disorders. $J$ Clin Psychiatry 2003; 64 (suppl 12): s1-s97.

10. Huang CC. Risperdal reduces alcohol use in dual disabled schizophrenia patients. Eur Neuropsychopharmacol 1996; 6 (suppl. 3): s43.

11. Casas M, Gutierrez M, Gibert J, Bobes J, Roncero C, Octavio I. Risperidona en el tratamiento de pacientes psicóticos con abuso y dependencia de opiáceos. Actas Esp Psiquiatr 2001; 29: 380-385.

12. Kingstone E, Kolivakis T, Kossatz I. [Double-blind study of clopenthixol and chlorpromazine in acute hospitalized schizophrenics]. Int Z Klin Pharmakol Ther Toxikol 1970; 3(1): 41-45

13. Huttunen MO, Piepponen T, Rantanen H, Larmo I, Nyholm R, Raitasuo V. Risperidone versus Zuclopenthixol in the treatment of acute schizophrenic episodes: a doubleblind parallel-group trial. Acta Psychiatr Scand 1995; 91: 271-277.

14. Glazer WM, Kane JM. Depot neuroleptic therapy: an underutilized treatment opinion. J Clin Psychiatry 1992; 53: 426-433.

15. American Psychiatric Association. Diagnostic and Statistical Manual of Mental Disorders (4th ed.). Washington DC: APA; 1994.

16. Kay SR, Fiszbein A, Opler LA. The Positive and Negative Syndrome Scale for Schizophrenia. Schizophr Bull 1987; 13: 261-276.

17. Guy W . ECDEU Assessment Manual for Psychopharmacology: Publication ADM 76-338. Rockville: US Department of Health, Education and Welfare; 1976. p. 217-222.

18. McLellan AT, Luborsky L, Woody GE, O'Brien CP. An improved diagnostic evaluation instrument for substance abuse patients: the Addiction Severity Index. J Nerv Men Dis 1980; 168, 26-33.
19. Chouinard G, Ross-Chouinard A, Annable L, Jones BD. The Extrapyramidal Symptom Rating Scale. Can J Neurol Sci 1980; 7: 233.

20. Lingjaerde O, Ahlfors UG, Bech P, Dencker SJ, Elgen K. The UKU side effect rating scale. Acta Psychiatr Scand 1987; 76 (suppl 334): s81-s94.

21. Roberts LJ, Shaner A, Eckman TA eds. Overcoming addictions. Skills training for people with schizophrenia. New York: W. W. Norton \& Company; 1999.

22. Hoyberg OJ, Fensbo C, Remvig J, Lingjaerde O, Sloth-Nielsen M, Salvesen I. Risperidone versus perphenazine in the treatment of chronic schizophrenic patients with acute exacerbations. Acta Psychiatr Scand 1993; 88: 395-402.

23. Marder SR, Meibach RC. Risperidone in the treatment of schizophrenia. Am J Psychiatry 1994; 151: 825835 .

24. Peuskens J. Risperidone in the treatment of patients with chronic schizophrenia: a multi-national, multi-centre, double-blind, parallel group study versus haloperidol. $\mathrm{Br} J$ Psychiatry 1995; 166: 712-726.

25. Marder SR, Davis JM, Chouinard G. The effects of risperidone on the five dimensions of schizophrenia derived by factors analysis: combined results of the North American Trial. J Clin Psychiatry 1997; 58: 538-546.

26. Schotte A, Janssen PFM, Gommeren W, Luyten WHML, Van Gompel P, et al. Risperidone compared with new and reference antipsychotic drugs: in vitro and in vivo receptor binding. Psychopharmacology 1996; 124: 57-73.

27. Yoshimura R, Nakamura J, Ueda N, Terao T. Effect of risperidone on plasma free 3-methoxy-4-hydroxyphenylglycol (pMHPG) levels in schizophrenic patients: relationship among plasma concentrations of risperidone and 9-hydroxyrisperidone, pMHPG levels, and clinical improvement. Int Clin Psychopharmacol 2000; 15: 175-180.

28. Möller HJ, Müller H, Borison RL, Schooler NR, Chouinard G. A path-analytical approach to differentiate between direct and indirect drug effects on negative symptoms in schizophrenic patients. Eur Arch Psychiatr Clin Neurosci 1995; 245: 45-49.

29. Möller HJ, Müller H. Statistical differentiation between direct and indirect effects of neuroleptics on negative symptoms. Eur Arch Psychiatr Clin Neurosci 1997; 247: $1-5$.

30. Davis JM, Chen N. Clinical profile of an atypical antipsychotic: risperidone. Schizophr Bull 2002; 28: 43-61.

31. Smelson DA, Roy A, Roy M. Risperidone and neuropsychological test performance in cocaine-withdrawn patients. Can J Psychiatry 1997; 42: 431. 
32. Buckley P, Thompson PA, Way L, Meltzer HY. Substance abuse among patients with treatment-resistant schizophrenia: Characteristics and implications for clozapine. Am J Psychiatry 1994; 151: 385-389.

33. Conley R, Gale E, Hirsch K. Olanzapine response in therapy-refractory schizophrenia with substance abuse. Schizophr Res 1998; 33: 95-101.

34. McEvoy J, Freudenreich O, McGree M. Clozapine decreases smoking in patients with chronic schizophrenia. Biol Psychiatry 1995; 37: 550-552

35. Brunette LM, Mueser KT, Xie H, Drake RE. Relationships between symptoms of schizophrenia and substance abuse. J Nerv Ment Dis 1997; 185: 13-20.

36. Zimmet SV, Strous RD, Burgess ES, Kohnstamm S, Green AL. Effects of clozapine on substance use in patients with schizophrenia and psychoaffective disorders: A retrospective survey. J Clin Psychopharmacol 2000; 20: 94-98.

37. Drake RE, Xie H, McHugo GJ, Green AI. The effects of clozapine on alcohol and drug use disorders among schizophrenic patients. Schizophr Bull 2000; 26: 441-449.

38. Marchi M, Raiteri M. Nicotine autoreceptors mediating enhancement of acetylcholine release become operative in conditions of impaired cholinergic presynaptic function. J Neurochem 1996; 67: 1974-1981.

39. Green AI, Zimmer SV, Strous RD, Schilkraut JJ. Clozapine for comorbid substance use disorder and schizophrenia: Do patients with schizophrenia have a rewarddeficiency syndrome that can be ameliorated by clozapine. Harv Rev Psychiatry 1999; 6: 287-296.

40. Rubio G, Jiménez- Arriero MA, Manzanares J, Ponce G, Palomo T. Tratamiento farmacológico de la esquizofrenia en pacientes con abuso/dependencia de drogas. In: Rubio G, Hernández JA, Jiménez-Arriero MA, Palomo T eds. Guía para el tratamiento de los pacientes con esquizofrenia. Madrid: Fundación Cerebro y Mente; 2002. p. 219-244.

41. Hutchison KE, Swift R, Rohsenow DJ, Monti PM, Davidson D, Almeida R. Olanzapine reduces urge to drink after drinking cues and a priming dose of alcohol. Psychopharmacology 2001; 155: 27-34.

42. Newton TF, Ling W, Kalechstein A, Uslaner J, Tervo K. Risperidone pre-treatment reduces the euphoric effects of experimentally administered cocaine. Psychiat Res 2001; 102: 227-233.

43. See RE, Aravagiri M, Ellison GD. Chronic neuroleptic treatment in rats produces persisting changes in GABA-A and dopamine D-2, but not dopamine D-1, receptors. Life Sci 1989; 44: 229-236.

44. Grace AA. Phasic versus tonic dopamine release and the modulation of dopamine system responsivity: a hypothesis for the etiology of schizophrenia. Neuroscience 1991; 41: 1-24.

45. Durell J, Lechtenberg B, Corse S, Frances R. Intensive case management of persons with chronic mental illness who abuse substances. Hosp Comm Psychiatr 1993; 44: 415-416.

46. Jerrell JM, Ridgley MS. Comparative effectiveness of three approaches to serving people with severe mental illness and substance use disorders. J Nerv Ment Dis 1995; 183: 566-576.

47. Mueser KT, Valentier DP, Agresta J. Coping with negative symptoms of schizophrenia: Patient and familiy perspectives. Schizophr Bull 1997; 23; 329-339.

48. Fridell M. Psychosocial Treatment for Drug Dependence. In: Beglund M, Thelander S, Jonsson E, eds. Treating Alcohol and Drug Abuse. Weinheim: Wiley-VC; 2003. p. 325-413.

49. Rubio G, Jiménez-Arriero MA, Ponce G, Palomo T. Naltrexone versus Acamprosate: 1 year follow-up alcohol dependence treatment. Alcohol Alcoholism 2001; 36: 419425 .

Address for correspondence:

Gabriel Rubio

Servicios de Salud Mental de Retiro

c/ Lope de Rueda, 43, 28009-Madrid, Spain.

Telephone: +34914008690

e-mail: garuva@inicia.es

SPAIN 